\title{
MULTIPLICANDO LA POBREZA AGRÍCOLA: CÓMO LA POLÍTICA AGRARIA COMÚN DE LA UNIÓN EUROPEA ESTÁ ESTRANGULANDO LA RECUPERACIÓN
}

\author{
BRIAN O'CAITHNIA*
}

Resumen: La Política Agraria Común (PAC) ha sido el orgullo del integracionismo europeo desde su concepción. Ha sido la máxima distinción de la tecnocracia y la última proclama de unidad de la posguerra europea. Durante décadas, sin embargo, la PAC también ha sido blanco de un número significativo de críticas por parte de muchos economistas debido a que consume una parte desproporcionada del presupuesto europeo, genera distorsiones en el mercado, dilapida fondos públicos y contribuye a generar desigualdades rurales. En este artículo intentaré transmitirle al lector cómo es que la PAC llegó a estar donde está hoy, cómo ha exacerbado el edificio tambaleante del dinamismo europeo en un continente enfermo y por qué un electorado educado es esencial si deseamos terminar con la habilidad para destruir riqueza que la PAC posee.

Palabras clave: Política Agraria Común, Crisis Económica, Reforma, Subsidios Agrícolas, Intervención.

Clasificación JEL: Q, Q01, Q18, Q28, Q57, Q58.

Abstract: The Common Agricultural Policy (CAP) has been the pride of European integrationism since its inception. It has been the crowning glory of technocracy and the ultimate statement of unity in post-war Europe. For decades however, the CAP has also come under a significant amount of criticism from economists for consuming a disproportionate share of the EU budget, introducing market distortions, wasting government funds and contributing to rural inequities. In this article I shall briefly bring the reader up to

* Máster en Economía de la Escuela Austriaca y estudiante de Doctorado, Universidad Rey Juan Carlos. 
speed with how the CAP got to where it is today, how it has exacerbated the tumbling edifice of European dynamism in a sick continent, and why an educated electorate is essential if we wish to bring the CAP's wealth destroying capabilities to an end.

Key words: Common Agricultural Policy, Economic Crisis, Reform, Agricultural Subsidies, Intervention.

JEL Classification: Q, Q01, Q18, Q28, Q57, Q58.

\section{I \\ INTRODUCCIÓN}

La Política Agraria Común (PAC) ha sido el orgullo del integracionismo europeo desde su concepción. Ha sido la máxima distinción de la tecnocracia y la última proclama de unidad de la posguerra europea. Fundada como parte del Tratado de Roma ${ }^{1}$ en 1957, la PAC se ha llevado, a veces, hasta el 70 por ciento del presupuesto de la Unión Europea ${ }^{2}$ y ha encarnado el deseo de la UE de mantener la autosuficiencia económica. La integridad de la PAC ha sido considerada por algunos como el tejido político esencial de la Unión Europea misma (Hasha 1999). Durante décadas, sin embargo, la PAC también ha sido blanco de un número significativo de críticas por parte de muchos economistas debido a que consume una parte desproporcionada del presupuesto europeo, genera distorsiones en el mercado, dilapida fondos públicos y contribuye a generar inequidades rurales. No obstante, ha sobrevivido a los muchos intentos por ser eliminada y ha adquirido la reputación de ser prácticamente imposible de reformar de alguna manera relevante.

1 Los Tratados de Roma son dos tratados firmados el 25 de Marzo del año 1957 por Bélgica, Francia, Italia, Luxemburgo, Holanda y Alemania Occidental. El primer tratado establecía la Comunidad de Energía Atómica Europea (EAEC, por sus siglas en inglés) mientras que el segundo establecía la Comunidad Económica Europea (el tratado de la CEE, a menudo referido como Tratado de Roma).

2 El presupuesto de la PAC representó casi el 75 por ciento del presupuesto europeo en 1985 (Dirección General de Desarrollo Agrícola y Rural, 2008). 
Existen pocos programas europeos donde uno encuentre un consenso político tan amplio dentro de los estados miembros. En el año 2005, el presidente francés Jacques Chirac dijo: «No estoy dispuesto a hacer la más mínima concesión sobre la Política Agraria Común... la PAC es el futuro» (Open Europe 2005, p. 3). José Luis Rodríguez Zapatero, el primer ministro español, dijo «En la reforma de la PAC, Francia y España mantienen una posición común» (Open Europe 2005, p. 3). Bertie Ahern, el primer ministro irlandés, dijo «Entiendo que las peticiones de reforma de la PAC están fuera de lugar porque se basan en una falta de comprensión respecto del rol de la PAC en la sociedad europea y en la economía mundial» (Ahern 2005).

La reciente crisis económica global ha echado por tierra la estabilidad financiera del Euro y ha generado preguntas respecto de la viabilidad de largo plazo de la «Unión cada vez más estrecha». ${ }^{3}$ En este artículo intentaré transmitirle al lector cómo es que la PAC llegó a estar donde está hoy, cómo ha exacerbado el edificio tambaleante del dinamismo europeo en un continente enfermo y por qué un electorado educado es esencial si deseamos terminar con la habilidad para destruir riqueza que la PAC posee.

\section{II \\ EL ESTABLECIMIENTO DE LA PAC (¿POBREZA AGRÍCOLA CREADA?)}

Tal como fueron expresados en el Tratado de Roma, los objetivos de la Política Agraria Común la dotaron de una política incoherente que, desde el primer momento, no podría ser alcanzada en la realidad. Estos objetivos, desplegados en el artículo 39 del Tratado de Roma, eran los siguientes:

1. Incrementar la productividad.

2. Asegurar estándares de vida equitativos para la comunidad agrícola.

3 Una «Unión cada vez más estrecha entre los pueblos de Europa» es uno de los objetivos establecidos en el Tratado de Roma de 1957. 
3. Estabilizar los mercados.

4. Asegurar la provisión de alimento.

5. Asegurar precios razonables al consumidor.

Cualquier lego reconocerá instantáneamente que los objetivos de la PAC son vagos y contradictorios. Metas tales como estabilizar los mercados e incrementar la productividad, por ejemplo, son irreconciliables. Incrementar la productividad agrícola, en esencia, desestabiliza los mercados al rebajar los precios del alimento y, como consecuencia, los ingresos de los productores. Viendo que ambas políticas no podían ser enteramente perseguidas de manera simultánea, pronto se hizo evidente que la productividad se sacrificaría frente al altar de la nómina de los agricultores. Entre las múltiples metas originalmente proclamadas por la PAC, los ingresos estables y políticamente aceptables de los productores agrícolas han demostrado ser la preocupación primordial de los funcionarios de la Unión Europea. La sensibilidad política de los ingresos agrícolas es consecuencia del hecho de que Europa tiene una larga historia de proteccionismo con el sector agricultor y que la porción de mano de obra europea empleada en ese sector siempre ha sido mucho mayor que la porción de producto interno bruto (PIB) atribuible al valor bruto añadido en el sector agrícola.

Para 1962, los detalles ya estaban listos y estaba decidido que la PAC operaría sobre la base de tres principios fundamentales: 1) libertad de comercio dentro de la Comunidad Europea basada en principios comunes, 2) preferencia por productos de la Comunidad en los mercados de la Comunidad y 3) responsabilidad financiera conjunta.

Empleando una variedad de mecanismos, la PAC original brindaba una ayuda general al mantener los precios internos - de cantidades ilimitadas de la mayoría de los productos- estabilizados en un nivel muy superior al de los precios internacionales. La PAC aisló a los mercados domésticos de las fuerzas del mercado internacional, evitando que los productores de la Comunidad Europea realizaran los ajustes que de otra manera habrían sido necesarios. Cuando durante los primeros años de la PAC la Unión Europea era importadora neta de la mayoría de los productos 
agrícolas, el presupuesto europeo se beneficiaba de los sustanciosos ingresos generados por los impuestos a las importaciones mientras que el costo del apoyo al sector agrícola provisto a través de los elevados precios internos recaía mayormente en los consumidores. Como explica Bryan Caplan en su trabajo «El Mito del Votante Racional», aparece un sesgo a favor de la creación de trabajo (make-work bias) entre la gente que vota donde se aprecia una «tendencia a subestimar los beneficios económicos de ahorrar en mano de obra» (Caplan 2007, p. 40). Él toma los subsidios a la agricultura como ejemplo para los Estados Unidos, donde estos son populares tanto en estados agrícolas como en estados no agrícolas. Las elecciones sugieren que la gente concuerda con la idea de que los subsidios agrícolas son necesarios para garantizar un abastecimiento seguro de alimento en contra de los economistas, por el otro lado, que ven a los subsidios como dispendiosos e innecesarios para alcanzar estos fines. A continuación se pregunta: «¿Por qué nadie escucha a los economistas?» Uno podría pensar que la gente simplemente no ha pensado acerca de ello, pero incluso cuando están bien explicados, los análisis de los economistas no resultan persuasivos ni interesantes para mucha gente. De aquí que cada vez más los consumidores se conviertan en «ignorantes racionales» respecto del hecho de que están pagando precios elevados por su comida - no vale la pena el esfuerzo de informarse, protestar o darle importancia.

A menudo se responsabiliza a los franceses por la PAC (Zobbe 2002). Muchos ven a los alemanes como las pobres almas forzadas a aceptar la PAC como precio a pagar por obtener un mercado libre de bienes industriales. ${ }^{4}$ Sin embargo, debemos hacer notar que la agricultura alemana se oponía a la política porque temía que la PAC redujese sus barreras proteccionistas, que eran

\footnotetext{
${ }^{4}$ El nuevo Ministro de Agricultura francés «... condujo las discusiones por la primera PAC. Los alemanes trataron de bloquear cada paso. Adenauer (Primer Ministro Alemán) estaba bajo la presión enorme de los agricultores, la gran mayoría de su propia coalición e incluso intereses comerciales para rechazar la PAC... En sucesivas rondas de negociaciones, de Gaulle se enfrentó a Erhard, no a Adenauer. La cooperación política también fracasó. Ahora tomó una línea más dura. Informó a su gabinete a principios de 1963 que si la PAC no se completaba pronto "no habría más Mercado Común"» (Pearsons, 2003).
} 
las más altas de Europa hasta el momento. El lobby agrícola en Alemania venía manteniendo al país cautivo desde los días de la pared tarifaria de Otto von Bismarck. Con los precios mínimos más elevados de la Comunidad Económica Europea, Alemania temía que la armonización implicara dolorosos recortes de precios para sus políticamente influyentes productores agrícolas.

\section{III LA DISOLUCIÓN DEL COMERCIO AGRÍCOLA EN EUROPA}

En 1968 se introdujeron las cuotas para el azúcar refinado como una manera de combatir las excesivas «montañas de alimento» que estaban acumulándose tal como los economistas norteamericanos habían previsto. ${ }^{5}$ Poco tiempo después, en 1969, una sexta parte de la cosecha de trigo de la Unión Europea debió ser desnaturalizada. Dado que su consumo dejó de ser apto para los seres humanos pero todavía podía ser consumida por animales, fue subsidiada como alimento animal en un intento por equilibrar demanda y oferta. En los '70 creció el temor de que la PAC fuera a desestabilizar a la Unión Europea en su totalidad. Los excedentes «estructurales», el incremento del costo presupuestario, las desigualdades entre los agricultores en términos de los beneficios de la PAC y las amenazadas relaciones internacionales contribuyeron a generar un intento de reforma. Esto llevó al principio, adoptado en 1982, de que los productores debían aceptar menos apoyo si superaban un nivel límite de producción. «Los Umbrales de Garantía» fueron adoptados para la leche, el azúcar, los cereales y los tomates procesados. Reformas posteriores, en 1984 y 1986, impusieron cuotas para la distribución de leche e introdujeron subvenciones a los precios. En 1988, la comisión de

5 «Parecería que la producción podría fácilmente ser incrementada a un ritmo mínimo del dos por ciento o más anualmente - casi el doble de la tasa de crecimiento de la demanda anticipada. Si esto tuviera lugar, la demanda neta europea de alimentos no tropicales importados se reduciría en algún momento de finales de los ' 60 y desaparecería prácticamente durante la década siguiente»(Coppock, 1963, p. 173). 
la UE, célebre por su honestidad, anunció al mundo que «para la mayoría de los productores, las compras gubernamentales de apoyo ilimitadas son cosa del pasado». Como veremos más adelante, un tigre no cambia sus rayas.

IV

\section{LA PAC: UNA BESTIA CON CABEZA DE HIEDRA}

Muy similar a la mítica Hiedra a quien le crecían nuevas cabezas cuando una era cortada, cuando las justificaciones económicas para la PAC dejaron de ser efectivas para frenar cualquier tipo de reforma significativa, una plétora de nuevos argumentos emergió de las cenizas para reemplazarlas. Ayudada por brotes de enfermedades como la EEB (1997) y la fiebre aftosa (2001) y el crecimiento del cambio climático como justificativo para la expansión del poder gubernamental, la política de la PAC se ha apartado de los motivos tradicionales en que se apoyaba. Esto culminó en la futura declaración de los más destacados economistas agrícolas titulada «Una Política Agraria Común para los Bienes Públicos Europeos» (ECIPE, 2009), donde se propuso un cambio en los objetivos de la PAC. La declaración argumentaba que los objetivos clave hasta el momento - incrementar la eficiencia agrícola, cambiar la distribución del ingreso en la UE, y fomentar el desarrollo rural- no deberían seguir teniendo un rol preponderante. La búsqueda de cantidad demandada por los precios mínimos de la PAC comprometía la calidad, la seguridad y la ecología. En lugar de ello, la PAC debía basarse en argumentos medioambientales. Esto incluye contribuciones a la lucha contra el cambio climático, la protección de la biodiversidad y una administración del agua que pueda lidiar con la contaminación, la escasez y las inundaciones. Los economistas concluyeron que la futura PAC debía ser fundamentalmente diferente de la vigente hasta el momento. La intervención en los mercados agrícolas, por ejemplo, mediante subsidios a las exportaciones y el sistema de Pago Único por Explotación que otorga un apoyo al ingreso agrícola sin demandar algo de producción a cambio, debía ser progresivamente eliminada. 
El actual comisionado agrícola de la UE, Dacian Ciolo (2010) ha proclamado una «verdización de la PAC». Incluso el comisionado medioambiental de la UE, Janez Poto Nik llegó al punto de decir que él ve «en algún momento del futuro» una política europea llamada «La Política Agraria y Medioambiental Común» (Poto nik, 2010). En sus palabras: «Necesitamos nada menos que una PAC que respete [el suelo y el agua] y promueva prácticas que los usen en una forma sostenible y recurso-eficiente. También necesitamos una PAC que pueda invertir en protegerlos y restaurarlos cuando éstos hayan sido degradados o contaminados». Franz Fischler, un ex comisionado agrícola de la UE y actual director de la fundación RISE para el desarrollo rural se lamentaba de que cuando la PAC fue introducida originalmente la actividad se intensificó como resultado de las compras ilimitadas a precios artificialmente altos. ${ }^{6}$ Ahora dice que la PAC debería «superar la seguridad alimenticia» haciendo que la política de la UE provea bienes y servicios públicos ecológicos.

Pero ¿qué quiere decir con bienes públicos? Los bienes públicos significan cosas distintas para las diferentes partes interesadas. En la literatura, Samuelson (Samuelson, 1954) y otros han argumentado que un déficit en la producción de bienes públicos, comparado con la escala de la demanda pública, apuntala el caso en favor de la intervención pública, y que asegurar la provisión de bienes públicos es una razón válida para la intervención estatal. Este argumento en favor de la intervención da lugar a una variedad de sectores o ramas de las políticas públicas tales como el agua potable, la «biodiversidad» y el «clima estable».

Al emplear la teoría de los bienes públicos y amalgamarla con el ecologismo y el cambio climático, el lobby agrícola ha logrado secuestrar las economías de Europa. Los biocombustibles, por ejemplo, en los últimos años se han abierto paso rápidamente en el mercado del combustible para trasporte. Según el Programa de Naciones Unidas para el Medio Ambiente, la producción mundial de etanol para combustible de transporte se triplicó entre los años 2000 y 2007 elevándose desde 17 mil millones de litros a más

${ }^{6}$ La Rural Investment Support Foundation (RISE) es un lobby pro PAC fundado en el año 2006. 
de 52 mil millones a nivel mundial, mientras que la producción de biodiesel se multiplicó por once desde menos de mil millones a casi 11 mil millones de litros (UNEP, 2009, p. 33). Un período de precios del petróleo elevados incrementó aún más la producción de etanol y biodiesel en el año 2008. Los principales países productores de biocombustibles para el transporte son, por supuesto, los Estados Unidos, Brasil y la Unión Europea. Brasil y los Estados Unidos subsidiaron el 55 y el 35 por ciento, respectivamente, de la producción de etanol mundial en el 2009 y la Unión Europea subsidió el 60 por ciento del total de biodiesel producido. La producción de los Estados Unidos consiste en su mayoría en etanol de maíz; en Brasil el producto principal es el etanol de la caña de azúcar; y en la Unión Europea la mayoría de los biocombustibles es biodiesel de colza (UNEP, 2009, p. 15).

El principal estímulo para este crecimiento extraordinario en el uso de biocombustibles ha sido la introducción de políticas de fomento al abandono de la producción de combustibles fósiles para el transporte automotor.

La política de biocombustibles de la UE ha ido evolucionando con los años desde un modesto apoyo a la producción de etanol como subproducto agrícola, hacia la elaboración de mandatos para la producción de combustibles de fuentes renovables. El excedente en la producción de vino fue quitado de los mercados durante décadas y utilizado en gran medida como bioetanol. La Unión Europea aprobó incluso una legislación en el 2008 que obligaba a usar biocombustibles en el sector del trasporte. Como parte de su «Paquete para el Cambio Climático», la UE adoptó la Directiva para la Energía Renovable (DRE, por sus siglas en inglés) en 2009 que fijaba un objetivo de 10 por ciento para que la energía utilizada en el transporte proviniera de fuentes renovables en el año 2020 (Comisión Europea, 2008) junto con el requisito de que el 20 por ciento de toda la energía proviniera de fuentes renovables (incrementándose desde el 8 por ciento del año 2009). Los mandatos relativos a los biocombustibles, las concesiones impositivas y el apoyo a las políticas aduaneras profundizan el vínculo entre los mercados de productos agrícolas y de energía. En lugar de traer mayor estabilidad, estas políticas relativas a los biocombustibles incrementaron la volatilidad de los precios 
agrícolas al hacer dependientes también a sus mercados tanto del nivel como de los precios del petróleo.

Mientras los productores agrícolas pueden simplemente querer un ingreso más estable para sí mismos, los que promueven una PAC «más verde» son más ideológicos. Como Franz Fischler comenta decepcionado:

En líneas generales, veo al desarrollo agrícola y rural de Europa sufrir los fallos del mercado, los recortes al presupuesto público y la ignorancia pública. La seguridad del alimento y del pienso, el cambio medioambiental y climático se encuentran en un camino insostenible. Al expandir la producción, los administradores de la tierra europeos han estado produciendo «bienes» medioambientales insuficientes tales como hábitats, especies y paisajes culturales, y muchos «males» medioambientales tales como contaminación de la atmósfera, la tierra y el agua. Esto es un símbolo de los fallos del mercado. (Fischler, 2010, p. 1).

$\mathrm{Al}$ recompensar generosamente la producción a cualquier precio, la PAC ha llevado a la intensificación de la agricultura en Europa. Paolo Bruni, presidente del lobby agrícola Copa-Cogeca, paraguas europeo de las cooperativas agrícolas, hacía notar que al introducir costosas regulaciones y obligaciones a los agricultores al tiempo que no se expanden los subsidios de manera simultánea, la agricultura de la UE se ve artificialmente condenada a realizar agricultura intensiva. En particular, suele ignorarse que la agricultura también tiene efectos colaterales negativos para la sociedad: el agua es extraída de los ríos y contaminada con fertilizantes y pesticidas. Cuando esto sucede se suele decir que existe una «externalidad de mercado» y ello se utiliza para justificar una expansión del poder del gobierno para monitorear y asignar recursos y derechos de propiedad. Las externalidades a las que economistas como Samuelson hacen referencia emergen cuando los derechos de propiedad no se encuentran claramente definidos (Mises, 1940, pp. 599-605).

Sin embargo, todo esto es una palabrería insulsa puesto que incluso ahora hablar de la nueva eco-condicionalidad de los subsidios directos para los agricultores no tiene mucho sentido dado que ya existen requisitos de cumplimiento cruzado (cross-compliance) 
y se espera que los productores respeten las leyes medioambientales de la UE. Hasta hace poco, la Unión Europea no se regía por el principio de "pagar al contaminador para que no contamine» sino por el «principio del contaminador-pagador» (PPP, por sus siglas en inglés). Si contaminas, deberías estar recibiendo una acción civil de todas formas, no solamente quedarte sin subsidios.

Paolo Bruni señala que «Si la producción no fuera económicamente viable, muchas regiones de la Unión Europea se verían obligadas al abandono de tierras. Esto podría destruir las enormes inversiones que los productores agrícolas y sus cooperativas han puesto en marcha» (Ryan, 2010). Aquí podemos ver el embrollo incoherente que significa la justificación medioambiental de la PAC. Por un lado abogan por políticas para proteger la naturaleza pero que aceleran la contaminación y la intensificación de la producción agraria. Por el otro lado, proponen el subsidio a los agricultores para mantener «la herencia agraria europea» lo que supone mantener más tierra en producción y pone a los granjeros nuevamente en la situación inicial de producción intensiva como requisito para la subsistencia.

\section{$\mathrm{V}$ \\ LA PAC: LA GRAN ANIQUILADORA DE LA COMUNIDAD AGRÍCOLA}

Además de mantener los precios artificialmente altos, castigar a los consumidores europeos y bloquear las importaciones de los países en vías de desarrollo llevando a la quiebra a los productores del tercer mundo, la PAC también ha fracasado en su objetivo de proteger el trabajo de los productores agrícolas y estabilizar sus ingresos. Solamente entre los años 1995 y 2000, los ingresos agrícolas cayeron un 70 por ciento (Open Europe 2005, p. 11). Esta caída se dio de manera concurrente con la caída en la proporción de pequeñas explotaciones en el número total de explotaciones lecheras. Se estima que dicha proporción caerá desde el 70 por ciento del año 1990 hasta menos del 10 por ciento en el año 2009 mientras que la proporción de grandes explotaciones crecerá desde 3 hasta el 45 por ciento para el año 2020 (Jongeneel, 2010). A pesar 
de la propaganda diciendo que la PAC se lleva a cabo en nombre del pobre pequeño productor, la abrumadora mayoría de los beneficios va a parar a los proveedores de input y a los grandes latifundistas (Open Europe 2005, p. 11). La OCDE estima que solo el 25 por ciento del valor total de los subsidios a la producción es realmente ganancia del productor. Los beneficios a los granjeros han aumentado también en una medida mucho menor que los presupuestos públicos ya que los pagos directos están destinados en gran medida a contrarrestar la caída en los precios internacionales. En el Reino Unido, por ejemplo, se ha dado el caso de que el 20 por ciento de las fincas y negocios agrícolas se llevaron el 82 por ciento de todos los subsidios de la PAC, mientras que el último 20 por ciento recibía solo un 0,05 por ciento. Como Jack Thurston, cofundador de FarmSubsidy.org ha mencionado: «Cuanto más grande eres, más subsidios recibes... Es al revés de lo que piensas que es un subsidio» (Walt, 2010). El absurdo se puede ver también en el hecho de que la UE gasta un poco menos de mil millones de euros al año (cerca del 2 por ciento del presupuesto total de la PAC) en subsidios al tabaco, pero al mismo tiempo promueve y fomenta programas para no fumar. La PAC es el sistema mundial más grande de subsidios agrícolas, con un gasto de 55 mil millones de euros en 2010 (Comisión Europea, 2010). Como podemos ver aquí, la UE utiliza los subsidios a las exportaciones en una escala muy superior a la de todos los demás países combinados (Gráfico 1).

El gráfico 1 resume los niveles totales de utilización de subsidios a las exportaciones (convertidos a dólares estadounidenses) de todos los países miembros que publican estadísticas al respecto para el período 1995-2002. La publicación de estadísticas sobre los subsidios a las exportaciones por parte de los países que participaron, en Uruguay, de la ronda de negociaciones comerciales del GATT fue llevada a cabo de común acuerdo por todos. Sin embargo, ha habido una quiebra en la actual ronda de Doha albergada por la Organización Mundial de Comercio que comenzó en el 2001 como resultado del rechazo por parte de los Estados Unidos y de la Unión Europea a cualquier tipo de compromiso respecto de sus políticas agrícolas. La conformidad con la publicación de informes sobre los subsidios a las exportaciones casi se termina 
PORCENTAJE MUNDIAL DE SUBSIDIOS DE APOYO DOMÉSTICO

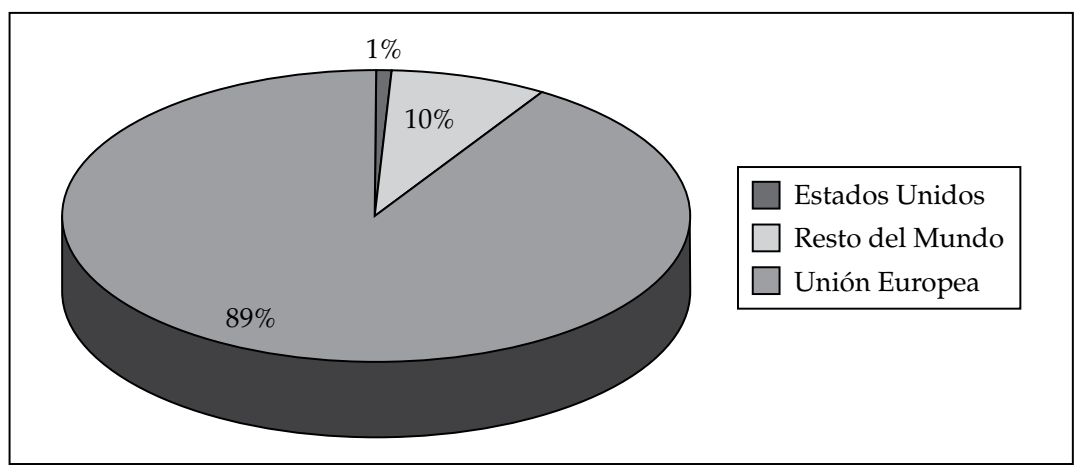

Fuente: Economic Research Service. USDA (USDA, 2010).

por completo durante las negociaciones del año 2003, haciendo difícil determinar cuáles son en la actualidad los porcentajes de subsidios a las exportaciones. Es razonable estimar que el gráfico de más arriba se asemeja a un informe actualizado.

No tiene ningún valor que los números del Eurostat hayan mostrado «a los agricultores como un grupo en la mayoría de los países de la UE-15 (al comienzo del nuevo milenio) de ingresos promedio muy similares a aquellos de las familias en general en el mismo país (a excepción de Portugal)» (Ackrill, 2008). Como hizo notar un autor, este hallazgo nada pudo hacer para brindar mayor apoyo político a este tipo de estadísticas, al menos entre las familias agrícolas (Hill, 2008). Entre otras de las preocupaciones destacadas por Hill también se incluyen a grupos de agricultores que, en algunos países, se oponen a la publicación de información que muestre el ingreso total de los miembros así como a las diferencias de ingresos totales a través de los distintos países argumentando en los debates políticos que ello iría en contra de los «intereses nacionales». En un mes tan reciente como Noviembre del año 2010 la PAC, que en el pasado publicaba los importes pagados a los productores agropecuarios, dejó de publicar esta información describiéndola como la «obligación de publicar información personal» $\mathrm{y}$, de aquí, como un ataque contra la libertad individual (Thurston, Mulvad, y Alfter, 2010). Este es 
un comienzo asombroso, especialmente considerando que poco tiempo atrás este mismo año el ex viceministro de agricultura búlgaro, Dimitar Peychev, fue arrestado tras descubrirse que su hija de 27 años había recibido $781.456 €$ en subvenciones de la PAC en 2009, provenientes principalmente del Programa de Desarrollo Rural. En total, su esposa e hija recibieron un millón y medio de euros de la PAC mientras él era el responsable de la distribución del dinero destinado a políticas generales de la UE (Vaglenov y Balabanova, 2010). Un programa de redistribución que cuesta a cada familia europea cerca de $1.000 €$ al año y sin embargo le niega al público el acceso al conocimiento de quiénes son los que están beneficiándose de él, es una afrenta a la justicia y al sentido común. Como Valentin Zahrnt indica (2010):

La carga de la prueba para los subsidios agrícolas ha sido mal asignada en el pasado. Aquellos que defendían el status quo de la PAC se referían ampliamente a los bajos ingresos agrícolas y al peligro que acechaba la seguridad del abastecimiento alimenticio. Pero nunca mostraron evidencia contundente suficiente respecto de la incidencia de la pobreza entre las familias agricultoras y la eficiencia en las transferencias de la PAC hacia las familias pobres, o escenarios creíbles bajo los cuales la seguridad alimenticia de la UE no pudiera ser mantenida.

\section{VI \\ LA BÚSQUEDA DE UNA JUSTIFICACIÓN}

Con el colapso de la Unión Soviética y el sentir generalizado inclinándose en contra de la planificación centralizada a finales de los '90, la PAC parecía fuera de moda y arcaica. Consciente de esto, la Comisión Europea dejó de utilizar argumentos económicos para justificar la PAC y se esforzó por encontrar defensas nuevas, vagas y más subjetivas. Un ejemplo típico es el de Franz Fischler (2008, pp. 22-27):

Sin una PAC fuerte, sería muy difícil alcanzar una agricultura sustentable y orientada hacia la naturaleza. Por un lado, la tendencia de la agricultura industrial se llevaría a cabo a expensas del 
bienestar animal y los servicios medioambientales. Por el otro, las regiones menos favorables serían abandonadas dando como resultado una variedad de consecuencias negativas para las áreas rurales y urbanas y sus habitantes. Las áreas rurales forman una hermosa e importante parte de la cultura europea. La PAC debe tener su rol en salvaguardar esta herencia natural y cultural.

Otra manifestación de la propaganda alimentada por el lobby agrícola para defender las subvenciones es la propagación de románticos mitos bucólicos que incluyen la confusión de la moderna agricultura comercial con la herencia rural y la idea de que las políticas agrícolas actuales sirven para sostener valores sociales fundamentales. Los intereses agrícolas pueden explotar estos mitos para generar el apoyo público a sus programas. Como veremos, meter a todo el sector agrícola en el mismo programa de bienestar público ha contribuido, en realidad, a la despoblación y a la quiebra de la Europa rural.

En años más recientes, los intentos de reforma se enfocaron principalmente en generar pagos directos significativos a los agricultores, sin considerar los efectos secundarios. La principal entre las distintas propuestas fue el clamor por la «naturaleza multifuncional de la agricultura» que exige una remuneración para los agricultores por su rol como «comisarios del medioambiente» $\mathrm{y}$ el paisaje rural. La Comisión ha declarado que «La diferencia fundamental entre el modelo europeo y aquel de nuestros competidores más grandes radica en la naturaleza multifuncional de la agricultura europea y el papel que desempeña en la economía y el medioambiente, en la sociedad y en la preservación del paisaje, de donde emerge la necesidad de mantener los cultivos en toda Europa y salvaguardar los ingresos de los agricultores» (Comisión de las Comunidades Europeas, 1998).

Aun si aceptáramos tal meta como genuina, tales programas no promueven los objetivos declarados por la política de proteger los paisajes y la diversidad biológica de una manera inteligente. Por ejemplo ¿cómo podría alguien haber sugerido que la política de retirada de tierras de la producción (set-aside), donde se paga a los productores por no trabajar su tierra, sería algo agradable a la vista? También se da el caso de que los precios inflados de los productos ayudan a mantener beneficios agrícolas más elevados 
lo que, por tanto, hace que haya más tierra en uso. De esta forma, en nombre de un hermoso ecosistema, la UE paga simultáneamente a los productores para no cultivar ciertas tierras y subsidia el cultivo de otras extensiones que de otra forma quedarían sin explotar. Esto guarda semejanza con las políticas que los Estados Unidos implementaron como parte del «New Deal» en los años '30:

Sin darse cuenta, los programas de la Oficina Agrícola Federal (FFB, por sus siglas en inglés) habían fomentado una mayor producción de trigo solo para evidenciarse en primavera que los precios caían rápidamente; los excedentes crecientes amenazaban el mercado y alentaron fuertes caídas. Se hizo evidente, en la impecable lógica de la intervención gubernamental, que los granjeros tendrían que reducir su producción de trigo si es que querían elevar los precios de manera efectiva. La FFB estaba aprendiendo la lección de todos los cárteles - la producción debía reducirse a fin de elevar los precios. Y la lógica del monopolio gubernamental de la agricultura también llevo a la FFB a concluir que los agricultores estaban «sobre produciendo». (Rothbard, 1963, p. 269).

\section{Luego Rothbard procedió a explicar:}

Y de esta forma el grandioso esfuerzo de estabilización de la Oficina Agrícola Federal fracasó estrepitosamente. Sus préstamos alentaron la mayor producción, que sumándose a los excedentes inundaron el mercado, rebajando más los precios tanto por razones directas como psicológicas. La FFB, entonces, empeoró la mismísima depresión agrícola que se suponía que debía resolver. Con la FFB generalmente reconocida como un fracaso, el presidente Hoover comenzó a empujar la inexorable lógica de la intervención hacia el segundo nivel: recomendar que la tierra productiva fuera retirada del cultivo, que las cosechas se destruyeran, y que los animales inmaduros fueran asesinados - todo para reducir los excedentes a los que, con anterioridad, el mismo gobierno había dado origen. (Rothbard, 1963, p. 273).

Los comisionados de la Unión Europea no son personas estúpidas. Están totalmente al tanto de lo vergonzoso que es tener excedentes que deben ser destruidos o desechados año tras año. Dándose cuenta de que no pueden proseguir para siempre con una política tan obviamente atrasada, las últimas reformas han 
ido en la dirección de promover un sistema de subsidios vergonzoso para los agricultores. En las reformas del año 2003, conocidas como Reformas Fischler, los subsidios directos fueron reemplazados por un sistema de pago único por explotación (SFP, por sus siglas en inglés) que se basaría en consideraciones de lugar y de subvenciones históricas sin relación alguna con la producción. Franz Fischler fue acusado de querer asesinar la PAC, pero hoy en día los sindicatos de agricultores reconocen ampliamente que él fue quien, de hecho, la salvó. ${ }^{7}$ Fischler creó una nueva criatura con la que los defensores del mercado libre deben enfrentarse, el Monstruo Verde, toda la teoría de los bienes públicos y la evidencia pseudocientífica sobre la que se encuentra fundamentada y que ha cautivado la imaginación popular.

\section{¿CÓMO FUNCIONA LA PAC EN LA ACTUALIDAD?}

En los últimos años, la UE ha dejado de enfocarse en un agresivo y explícito proteccionismo económico. Los lobistas han llevado al proteccionismo a formas cada vez más sofisticadas y difíciles de medir. Los «estándares de calidad» se han convertido en las nuevas barreras arancelarias. Por ejemplo, los estándares de la Unión Europea para proteger a los consumidores de la aflatoxina cuestan a los africanos exportadores de nueces, cereales y frutos secos 650 millones de dólares al año y reducen sus exportaciones en un 64 por ciento. El Banco Mundial estima que esta política que es extremadamente onerosa para mucho africanos puede prevenir una de cada mil millones de muertes por año en Europa (Open Europe, 2005, p. 15).

7 «Las organizaciones rurales de Europa admiten hoy que las reformas Fischler rescataron a la PAC y reconocieron que si Fischler hubiera cedido ante el pedido de Chirac de posponer las reformas hasta después de la ronda de la OMC, esto podría haber significado el final de la PAC como la conocemos. Sin reformas Europa no solo se habría quedado sin una base sólida y creíble para participar activamente en las conversaciones de la ronda de Doha sobre desarrollo, sino que también el acuerdo del Consejo Europeo de Bruselas no se habría sostenido frente a las presiones de los representantes del "uno por ciento" en relación con las perspectivas financieras para 2007-13» (Pirzio-Biroli, 2008). 
El gran tamaño del lobby agrícola europeo se ha asegurado siempre de que exista una resistencia considerable a toda reforma de la PAC. No obstante, a pesar de la posición privilegiada que los lobistas le han conseguido a la comunidad agrícola en su totalidad, la proporción del empleo agrícola en relación al empleo total se ha reducido en todos los países de la Comunidad Europea, haciendo que su posición privilegiada se vuelva cada vez menos segura. El rol de la agricultura en el empleo e ingreso total europeo ha decrecido drásticamente desde el origen de la PAC. La población rural de la UE ha ido reduciéndose en un promedio de 3 por ciento anual desde 1968, y el declive ha ido tomando velocidad: 4,5 por ciento anual desde 1986 a 1996 y ha caído en los países de la UE15 en un 18\% entre los años 1995 y 2005. Además, la contribución de la agricultura al PIB también ha continuado su declive aun más que el empleo en términos porcentuales. La agricultura de la Unión Europea empleaba poco más del 5,1 por ciento de la fuerza laboral de los países de la UE15 en 1996, pero representaba solo el 1,7 por ciento del PIB. También, los ingresos de las familias rurales han mejorado dramáticamente, igualando o sobrepasando los ingresos de las familias no rurales en la mayoría de los países de la UE (Comisión Europea, 1997). En la actualidad el ingreso promedio de las familias rurales, incluyendo las subvenciones agrícolas y el ingreso por actividades no agrícolas, se ha elevado hasta igualar e incluso superar los ingresos no rurales en casi todos los países de la UE. A pesar de que la población rural ha caído, ésta representa un voto «agrícola» crítico en muchos países europeos y los grandes beneficios destinados a los intereses rurales los han convertido en activos participantes de la vida política. Los beneficios de la PAC se han ido concentrando progresivamente en un número cada vez más pequeño de productores que son relativamente adinerados, reduciendo el apoyo popular a la PAC como fuente de asistencia a los necesitados (Open Europe, 2005). Sin embargo, los beneficios relativamente más pequeños destinados a un número más grande de pequeños productores siguen siendo importante para éstos, manteniendo un importante nivel de apoyo político para la PAC. Los países mediterráneos e Irlanda han sido los principales beneficiarios de la PAC y otros programas europeos. Un productor agropecuario en Grecia recibe 
más de $500 €$ por hectárea, mientras que un colega de Letonia recibe menos de $100 €$ por hectárea. Los ganadores y perdedores de la PAC pueden apreciarse en el gráfico siguiente.

GRÁFICO 2

PORCENTAJE DE INVERSIÓN EN LA PAC RETORNADA

A CADA PAÍS. (PAC 2010)

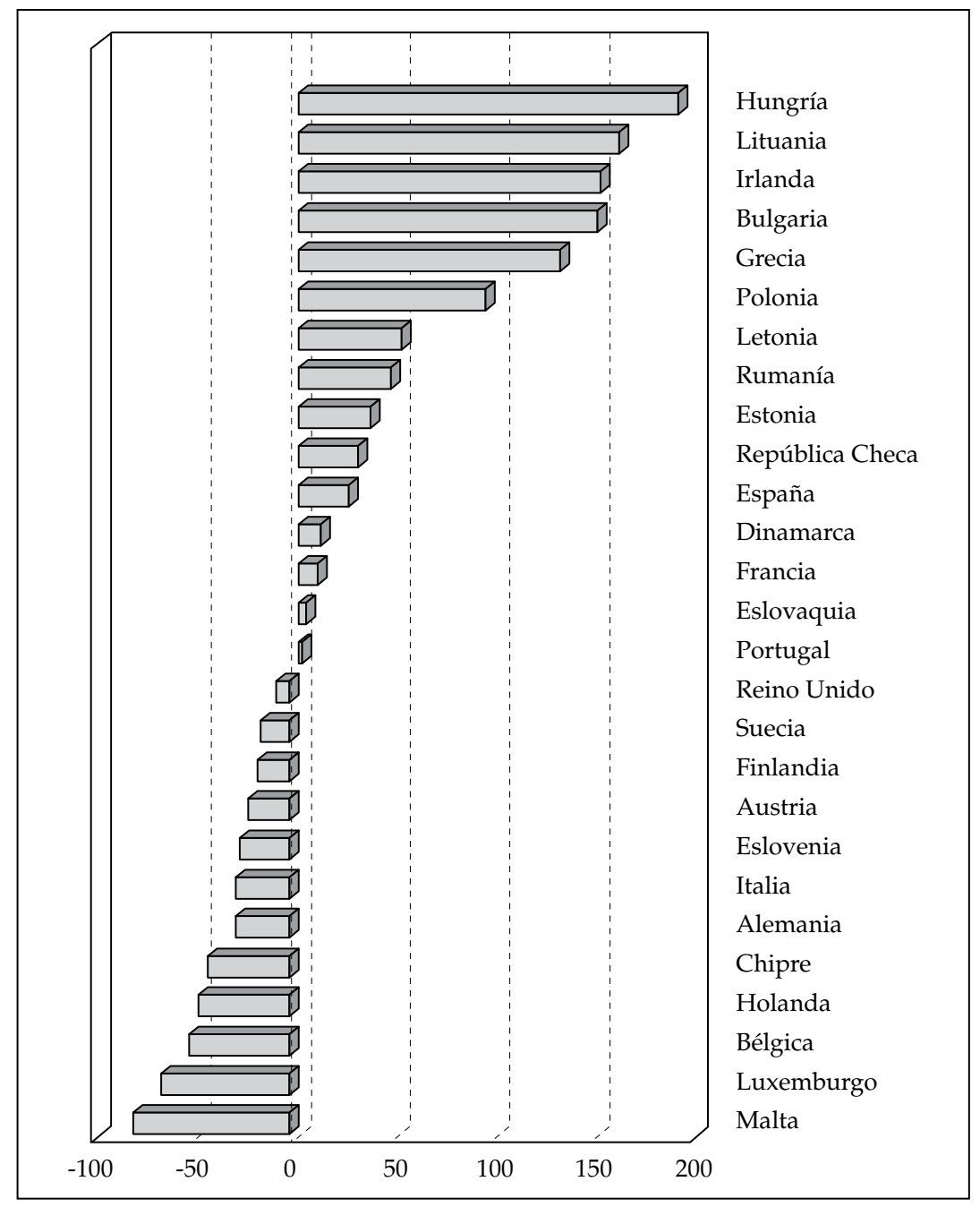


Alemania, y en menor medida el Reino Unido han sido los contribuyentes netos principales al presupuesto europeo. La posición política de Alemania como principal pagador ha sido complicada por su necesidad política - particularmente fuerte- de tener precios altos porque las explotaciones alemanas son relativamente pequeñas y los ingresos no rurales son relativamente elevados. Por su parte, el Reino Unido ha recibido un reembolso como compensación por contribuir significativamente más a la Unión Europea y recibir significativamente menos que otros países de la PAC. Los países del Benelux también parecen enfrentar la peor parte del acuerdo en relación con la PAC, pero uno debe recordar también que el monolítico edificio de la burocracia europea tiene su epicentro en estos países de manera que mientras tal vez sea el caso de que no se beneficien directamente de la PAC, sí reciben ciertos beneficios indirectos. Al comparar los siguientes diagramas se vuelve evidente quién está levantando la parte más pesada de la PAC y quiénes son los freeriders.

GRÁFICO 3

CONTRIBUCIONES NACIONALES AL APOYO DIRECTO DE INGRESOS

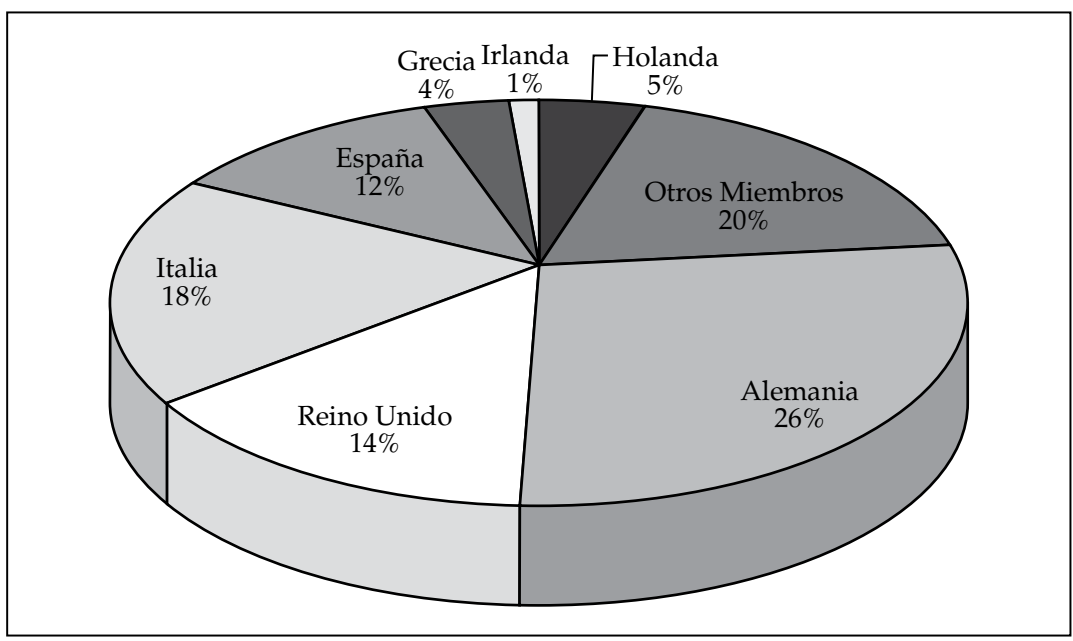

Fuente: Parlamento Europeo (2010). 
GRÁFICO 4

PERCEPCIONES NACIONALES DEL APOYO DIRECTO DE INGRESOS

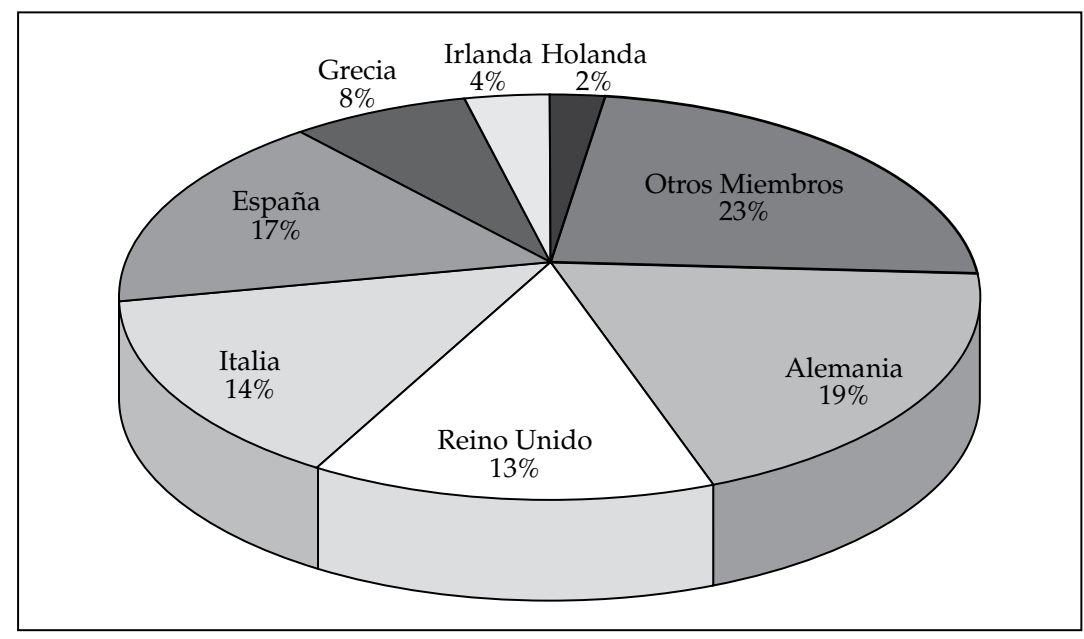

Fuente: Parlamento Europeo (2010).

VIII

¿QUÉ PASA CUANDO SE RETIRAN LOS SUBSIDIOS?

Nueva Zelanda eliminó de manera unilateral sus subsidios a mediados de los '80. Mientras la Unión Europea ha perdido cerca de un 40 por ciento de sus empleos agrícolas, el empleo rural en Nueva Zelanda se ha mantenido estable. Durante el mismo período, en Nueva Zelanda la producción creció un 150 por ciento en comparación con el 30 por ciento de crecimiento de la UE. Sin las subvenciones, muchos productores agrícolas se concentraron más en el valor que en el volumen, de manera que hay más importaciones, pero también más exportaciones con valor añadido. La producción y los ingresos netos de la producción lechera neozelandesa son más elevados ahora de lo que eran antes de que los subsidios se eliminaran -y el costo de producción de leche se encuentra entre los más bajos a nivel mundial (Rodale Institute, 2002). 
En 1990, los suecos también rechazaron la idea de que un fuerte apoyo al mercado podía ser justificado por algún objetivo «no económico» de la agricultura. En lugar de eso, cualquier externalidad medioambiental positiva debía ser remunerada mediante pagos directos. La filosofía subyacente era que las medidas de compensación/ajuste debían pagarse no porque las políticas del pasado hubieran creado automáticamente derechos a futuras subvenciones sino porque la sociedad tenía la obligación, en el sector agrícola y en cualquier otro, de abolir las políticas anteriores bajo condiciones socialmente aceptables.

En 1990 todas las regulaciones internas al mercado fueron abolidas lo que hizo de Suecia uno de los países con sectores agrícolas más desregulados en el mundo. A los productores solo se les ofreció una modesta y temporaria compensación y contrariamente a las reformas de la PAC, la reforma no se llevó a cabo a raíz de presiones externas o de una crisis presupuestaria.

Lamentablemente, casi todo debió ser revertido después de que Suecia tuviera que unirse a la PAC como requisito previo para ingresar en la UE en 1995. La política agrícola en Suecia estaba basada principalmente en un sistema de precios mínimos (Rabinowicz, 2004). El nivel total de subsidios en Suecia, medido por la Estimación de Apoyo al Productor (PSE, por sus siglas en inglés), era de 57 por ciento en 1990 y los precios del alimento eran muy elevados de acuerdo con los estándares internacionales. Las comparaciones ajustadas por el poder adquisitivo indicaban que los precios de la comida en Suecia se encontraban un 60 por ciento por encima del nivel de la Unión Europea, mientras que los precios en general eran solo de un 35-40 por ciento (Bolin, 1992). Además, los precios de los alimentos también se elevaron en términos reales durante la década del '80. En el año 2007, el máximo estandarte de la elite socialista europea, Suecia, se convirtió en el primer país de Europa en llamar a un abandono total de todas las subvenciones y regulaciones en el sector agropecuario con la única excepción de una pequeña cantidad destinada a subsidios medioambientales. Habiendo experimentado el dulce sabor de la libertad de mercado los suecos, naturalmente, rechazan el gasto burocrático de Bruselas. 


\section{IX ¿PUDO LA PAC REALMENTE ESTABILIZAR LOS MERCADOS?}

Al seguir las tendencias de su época, los tecnócratas ideólogos de la PAC estaban lo suficientemente confundidos como para todavía creer que podrían micro-dirigir el complejo súper sistema de la agricultura europea. El ganador del premio nobel de economía Friedrich Hayek pasó su vida luchando contra lo que llamó la «arrogancia fatal». Hayek consideraba que la idea de que el gobierno pudiera asignar los recursos de la sociedad de una manera más eficiente y racional que los propios individuos constituía uno de los mayores peligros para la humanidad en el siglo XX. En realidad, él observó que en la sociedad existe un insuperable problema de división del conocimiento al cual los gobiernos deben enfrentarse (Hayek 1948, p. 77; Huerta de Soto 2010, caps. 2 y 3).

A menudo se sugiere que el incremento en la productividad producto de la mejora en las tecnologías ha sido un resultado de la genialidad de la PAC que el mercado no podría proveer. Se ha dicho que una revolución tecnológica tuvo lugar como resultado de los mayores precios impulsados por la política de fijación de precios de la PAC. ${ }^{8}$ Sin embargo, la explosión real del crecimiento agrícola ocurrió en los países en desarrollo del tercer mundo donde no existen los subsidios, muy lejos de las protegidas fortalezas de Europa y de los Estados Unidos. Esto se convirtió en lo que en 1968 el director de USAID, William Gaud, llamó la «Revolución Verde» refiriéndose específicamente a países como la India donde la producción de bienes como los cereales se duplicaron en tan solo veinte años, entre 1961-1985 (Conway, 1998). Más aún, los subsidios de la PAC impidieron la consolidación de pequeñas explotaciones en otras de mayor tamaño y permitieron

8 «El incentivo que los precios altos le dan a la agricultura conlleva a una mayor inversión en planta y equipo capital y un reemplazo más frecuente de este equipo. De aquí que sea posible que el cambio tecnológico sea adoptado más rápidamente de lo normal, ya que mucha de la nueva tecnología está representada en nuevo equipamiento y se adopta para incrementar la producción en lugar de reducir los costes ya que el precio de venta está subvencionado» (Harvey, 1998). 
la existencia continuada de establecimientos ineficientes. Esto indicaría que cualquier avance tecnológico ha ocurrido a pesar de, en lugar de gracias a, las políticas de la PAC.

Los cambios globales han sido todos en la dirección opuesta a la de las políticas implementadas por la PAC. Por ejemplo, la población rural de los Estados Unidos en el año 1900 era de 29 millones; en el año 2000 había descendido a poco menos de 5 millones. En 1900 los productores agrícolas constituían el 39 por ciento de la población; en el año 2000, constituían poco más del 1,5 por ciento. Schumpeter (1942) describió impecablemente el proceso como uno de "destrucción creativa». A medida que las explotaciones más débiles e ineficientes son arrastradas a la bancarrota, nuevas oportunidades emergen y los recursos son liberados para que los empresarios alertas lleven a cabo una tarea de mejor asignación. En cualquier circunstancia, dado que los productores débiles e ineficientes son subvencionados por la PAC, el progreso tecnológico ha sido, en gran medida, retrasado. Además, dado que la PAC busca evitar los excedentes, parecería que la mejora tecnológica de la agricultura debería coincidir necesariamente con una política cada vez más restrictiva y más costosa (lo que, de hecho, ha sucedido).

Es más, contrariamente a los planes de autosuficiencia en la producción agraria, el déficit comercial en alimentos de los países de la UE27 es enorme y está en aumento, trepando desde 10,9 mil millones de euros en el año 2000 a 24,4 mil millones de euros en el año 2008 (de los cuales 13,3 mil millones están bajo la clasificación europea de "pescado») y solo en agricultura promediando los 6,6 mil millones de euros anuales desde 2000 a 2008. La tendencia más moderna fue la evolución reciente de los precios agrícolas en los mercados internacionales durante la crisis de los alimentos del año 2008. Tras décadas de asedio por parte de los gobiernos, las intervenciones comenzaron a dar sus frutos a medida que los precios comenzaron a elevarse rápidamente durante el período 2007-08. Como narraba un autor: "Ninguna persona sensata creía que la tendencia a la baja de los precios pudiera ser revertida. Pero esto ya no es cierto. No sabemos realmente cuáles serán los precios de los productos agrícolas pero podrían mantenerse elevados, basándose en estándares históricos, durante el futuro cercano. Y si eso 
sucede, sabemos que el futuro de la agricultura se verá profundamente afectado» (Petit, 2008). Muchos han acusado a la devastación agrícola de la PAC de ser un actor principal en el deterioro de los mercados internacionales de alimento. Al establecer lo que se conoce como «Fortaleza Europea» (Spoerer 2010), Europa todavía es una tierra rodeada de barreras proteccionistas. Agresivamente arroja millones de toneladas de comida a precios subsidiados a las economías del tercer mundo aniquilando a los productores locales. Como describe el informe anual del Programa de las Naciones Unidas para el Desarrollo de 2005:

En lo que respecta al comercio agrícola internacional, el éxito en el mercado no está determinado por las ventajas comparativas, sino por el acceso comparativo a las subvenciones - un área en la cual los productores de los países pobres no pueden competir. Los elevados niveles de subsidios agrícolas se traducen en mayor producción, menor importación y mayor exportación de la que prevalecería de no existir los subsidios. Este apoyo es lo que ayuda a explicar por qué los países industrializados siguen dominando el comercio internacional de productos agrícolas. (Human Development Reports, 2005).

Una política agrícola europea carente de reformas seguirá obstaculizando los esfuerzos de la Unión Europea y otros donantes por erradicar la pobreza y perpetuará el sufrimiento humano. Además, habiendo participado en la génesis del problema, ahora se congratulan porque la PAC es, de hecho, la «solución», ya que ahora pueden expandir sus cuotas debido a que los stocks mundiales de alimento se han vuelto demasiado pequeños (Barnier, 2008).

A pesar de todo esto, sin embargo, la Unión Europea sigue siendo el más grande importador de productos agrícolas de los países en vías de desarrollo y la agricultura europea después de todo sigue teniendo una posición débil. Si la comparamos con Norteamérica, un productor estadounidense produce seis veces más valor añadido que su contraparte europea (Csaki, 2008). En promedio, durante el período 2006-08, la Unión Europea ha importado 53 mil millones de euros en productos. Esto es más de lo que importan Estados Unidos, Japón, Canadá, Australia y Nueva Zelanda en conjunto. La Estimación de Apoyo al Productor (PSE), calculada 
por la Organización de Cooperación y Desarrollo Económico (OCDE), es un indicador del valor monetario anual de las transferencias brutas de los consumidores y contribuyentes a los productores agropecuarios. En el año 2009 la PSE total para todos los productos de la UE27 estaba valorada en casi 120 mil millones de dólares comparada con apenas 30 mil millones de dólares en los Estados Unidos (OECD, 2010). Como muestra el Gráfico 5, la Unión Europea es la principal contribuyente a las subvenciones de la OECD.

\section{GRÁFICO 5}

CONTRIBUYENTES A LAS POLITÍCAS DE APOYO DE LA OCDE

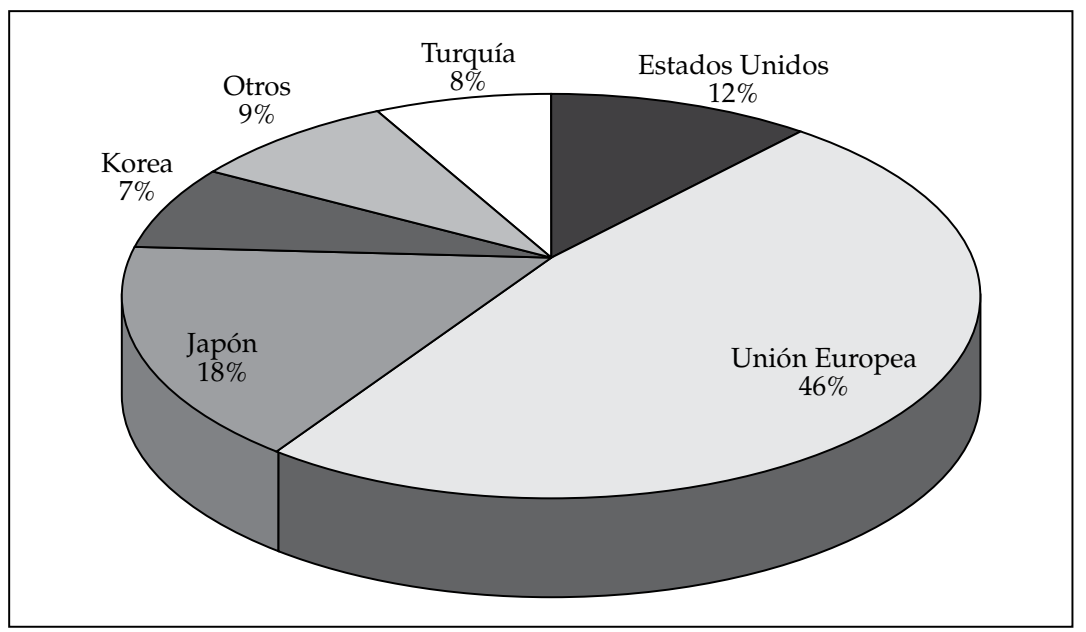

Fuente: Parlamento Europeo (2010).

Cuando los precios de los alimentos se dispararon en 2007/08, la seguridad alimenticia llegó a las portadas de los diarios y la maquinaria global gubernamental, como el G8, el Banco Mundial y la FAO (la Organización para la Alimentación y la Agricultura) se apresuraron a organizar cumbres y hacer declaraciones. Como describe Valentin Zahrnt:

Las preocupaciones acerca de los bajos ingresos agrícolas, la decadencia de las comunidades rurales y los beneficios para el paisaje 
de la agricultura, todos parecieron ser lujos desechables al ser comparados con la potencial amenaza a nuestra supervivencia. Así que la seguridad alimenticia se transformó en el más persuasivo y poderoso argumento para aquellos que claman por la protección europea de la agricultura. (Citado en Zahrnt, 2010).

La crisis alimenticia mundial de 2006/08, que vio cómo las existencias de alimento se erosionaban y los precios de bienes esenciales tales como el arroz y el trigo se incrementaban en un 217 y un 136 por ciento respectivamente, ha sacudido la profesión económica. En el año 2007, el Índice de Precios de los Productos Alimenticios calculado por la FAO subió cerca de un 40 por ciento, comparado con el 9 por ciento del año anterior. Durante décadas se supuso simplemente que siempre habría una tendencia a la baja de los precios alimenticios. Esta idea se encuentra ahora hecha añicos. A partir de las cenizas de la crisis alimenticia, la UE - como era de esperar - promocionó la PAC como la solución para cualquier crisis futura gracias a su sistema de almacenamiento para la posterior distribución estratégica en tiempos de necesidad. En el año 2010, la Comisión Europea anunció su intención de vender sus existencias de cereales a fin de estabilizar la situación después de que la prohibición en Rusia a la exportación de granos amedrentara a los mercados internacionales (EU Business Ltd, 2010). En el año 2007, en respuesta a una pregunta escrita del parlamento, el gobierno del Reino Unido reveló que a lo largo del año anterior el Stock Público de la UE había acumulado «13.476.812 toneladas de cereal, arroz, azúcar y leche y 3.529.002 hectolitros de alcohol/vino» que serían bien destruidos o bien subsidiados para que puedan exportarse. En términos globales, cerca de 100 millones de toneladas de granos por año están redirigiéndose desde los alimentos hacia los combustibles (Toepfer International, 2007). La producción total de granos para el año 2007 se situó apenas por encima de las 2 mil millones de toneladas. Incluso un informe del Banco Mundial concluyó en el mes de Julio de 2008 que «... grandes incrementos en la producción de biocombustibles en los Estado Unidos y Europa son la razón principal detrás de la vertical subida en los precios globales de los productos alimenticios» (Mitchell, 2008). El artículo terminaba 
por admitir que sin la producción artificialmente estimulada de biocombustibles en los Estados Unidos y la UE los aumentos en los precios habrían sido mucho menores.

Por supuesto, a pesar de las innumerables declaraciones acerca de la necesidad de mantener la seguridad alimenticia, lo que la UE ha logrado realmente ha sido que la seguridad alimenticia de miles de millones de seres humanos sea cada vez más precaria. El mismo Al Gore, el campeón global de los subsidios a los biocombustibles, ha sido el último en darse cuenta del error de su postura. En un discurso en Noviembre del año 2010 en una conferencia sobre energías renovables en Atenas, afirmó que «no es una buena política otorgar subsidios para el etanol (norteamericano) de primera generación... Creo que el etanol de primera generación ha sido un error. Los ratios de conversión de energía son, en el mejor de los casos, muy pequeños... Una vez que el programa echa a andar, es difícil lidiar con el lobby que lo mantiene funcionando» (Reuters, 2010). Y continuó diciendo «El tamaño, el porcentaje de maíz particularmente, que se está empleando ahora para etanol de primera generación decididamente tiene un impacto en el precio de los alimentos». Uno debe preguntarse ante semejante testimonio por qué siguen en pie este tipo de programas.

Se estima que el apoyo público a la agricultura en los países de la OCDE cuesta a una familia de cuatro un promedio de 1000 dólares anuales en forma de impuestos y precios más elevados. Incluso de acuerdo con el Informe sobre Desarrollo Humano del año 2003 cada vaca lechera recibió 913 dólares anuales en subsidios durante el año 2000 en la Unión Europea, mientras que tan solo un promedio de 8 dólares por ser humano se destinaba a programas de ayuda al África Subsahariana. Si bien la PAC ha cambiado de manera significativa en los últimos diez años y ya no existen subsidios especiales para los vacunos, se trata simplemente de un reordenamiento de las sillas situadas sobre la cubierta del Titanic ya que el presupuesto total destinado a la producción agrícola no ha sido modificado. 


\section{$X$ ¿QUÉ ES LO QUE REALMENTE GUÍA LA PAC?}

Es interesante notar que el objetivo de la «seguridad alimenticia» que tradicionalmente se había esgrimido para justificar la PAC ha sido abandonado por la Comisión Europea (Comisión Europea, 2009). Sin embargo, Michel Barnier, Ministro de Agricultura francés durante el período 2007-09 y ex comisionado y miembro del gobernante partido de centroderecha UMP ha convocado a Europa para establecer un plan de seguridad alimenticia y resistir recortes adicionales del presupuesto agrícola europeo. "Se trata de asegurarse que las generaciones futuras no paguen un precio también». Con hábil timing político, el Ministro de Agricultura atacó a los mercados protestando porque «Lo que estamos viendo ahora en el mundo es la consecuencia de demasiado capitalismo de libre mercado... No podemos dejar la alimentación de las personas a la merced del mercado. Necesitamos una política pública, un medio de estabilización y de intervención» (Hall, 2008).

A principios de los años sesenta economistas norteamericanos como Tunman y Learn fueron extraordinariamente proféticos al observar que la PAC buscaría exportar los problemas europeos. El francés Michel Barnier también ha invitado a África y Latinoamérica a crear sus propias versiones de la Política Agraria Común europea como respuesta a la creciente demanda de alimentos, diciendo:

Yo creo que [la PAC] es un buen modelo. Es una política que nos permite producir para alimentarnos nosotros mismos. Unimos nuestros recursos para apoyar la producción. África Occidental, África Oriental, Latinoamérica y la costa sur del Mediterráneo todos necesitan políticas agrarias comunes y regionales. (Hall, 2008).

Mientras los críticos de la PAC se preparan para usar los precios crecientes y las amenazas de escasez de alimentos para conseguir un comercio más libre en el sector agrícola, Barnier ha mantenido firme su posición de no dejar que el sistema europeo de 
subsidios y barreras al comercio sea el chivo expiatorio del «desorden» existente alrededor del alza en los precios de los commodities y el descontento asociado a él en muchos países.

\section{1. ¿Existe alguna resistencia?}

A pesar de todo, existe un creciente sentimiento en contra de la PAC. En el año 2000, una revista especializada analizando la PAC publicaba el siguiente comentario:

Es, tal vez, incluso más interesante que la actual justificación para la continuada existencia de la PAC - la agricultura multifuncional- no aparezca en ninguno de estos comentarios. Si lo hiciera, tal vez al menos uno podría haberse escrito a modo de obituario, cuando no como nota de despedida. Seguramente el título -Política Agraria Común - se ha vuelto ahora más anacrónico que la URSS, una contradicción, si no una verdadera mentira en cada palabra. (Harvey, 2008).

Y continúa diciendo:

Si la única justificación sostenible para cualquier tipo de política relativa a la agricultura (y/o al uso de tierras rurales) es aquella de los fallos del mercado (como sugieren implícitamente los argumentos de multifuncionalidad), entonces se sigue que las razones para la intervención (y de ahí el diseño de políticas y objetivos) deben también diferir, tanto en cantidad y en tipo, a lo largo del espacio, el territorio $y$, consecuentemente, a través de los distintos países. La noción y el concepto de una política común es inherentemente contradictorio si no vacío de sentido, como [Csaki, 2008] señala; los miembros actuales de la UE tienen requisitos muy diferentes en términos de cantidad y también en el tipo de política.

De momento, los planes de la PAC son que los gastos en políticas de apoyo al mercado y al ingreso agrícola, su pilar principal, se reduzcan eventualmente a un 32 por ciento del total del presupuesto europeo para 2013, un cambio significativo si se lo compara con el 70 por ciento que se llevaba a principios de los 
ochenta. Además, habrá mucha presión sobre las finanzas de la PAC de 2013 en adelante porque los diez nuevos miembros de la UE que previamente solo recibían el $25 \%$ del total de la tasa europea, en el año 2004 recibirán el 100 por ciento del nivel de apoyo de la PAC que se aplica en la UE actualmente.

Sin embargo, la defensa intelectual de la PAC está menguando entre el público. La profesión económica está volviéndose cada vez más valiente en sus ataques contra la PAC. Como indicaba un autor recientemente, «los costos asumidos por los contribuyentes y los consumidores son más grandes que los beneficios de los productores agrícolas porque los precios altos expulsaron la demanda de consumo y la expansión subsidiada de la agricultura europea limitó la disponibilidad de recursos como el trabajo y el capital que podrían haber sido utilizados de manera más productiva en otros sectores de la economía. De aquí que la PAC no solo sea un juego de suma cero.» (Peeters, 2008).

En el mundo del posmodernismo económico podemos encontrarnos con defensas de la PAC tales como «... la PAC [es] una parte fundamental de nuestro estado de bienestar europeo y su economía "moral" ... tiene una justificación política» (Rieger, 2005). La argumentación a favor de la PAC esta volviéndose cada vez más absurda y gran parte del lenguaje filantrópico concreto que rodeaba su creación está siendo dejada de lado. Como (Rieger, 2005) expone con orgullo: «La PAC es una política orientada hacia el interior por excelencia. Su tarea nunca fue la de incrementar el bienestar del mundo sino asegurarse que los productores agrícolas de Europa se encontraran a salvo en ella.»

Podemos estar de acuerdo con Rieger en que la PAC no ha mejorado el nivel de vida del mundo. Pero se equivoca al pensar que los productores agrícolas se encuentran a salvo en Europa. La PAC ha bloqueado la agricultura europea y ha eliminado el incentivo empresarial del sector. El productor agrícola europeo ha mutado desde ser el eje central de una otrora fecunda industria agrícola a ser un simple engranaje impotente de la maquinaria política. La PAC ha sido la protagonista de la reducción de abastecimiento alimenticio, fomentando en el proceso una nueva era de escasez, irónicamente la supuesta razón que fue empleada para justificar la PAC en un primer momento. 


\section{$\mathrm{XI}$ \\ ¿HA MEJORADO LA PAC DESPUÉS \\ DE TODAS LAS REFORMAS?}

El lechero fue el único sector en experimentar una caída significativa en el nivel absoluto de gasto durante las reformas del 2003 (el «Chequeo de Salud» de Franz Fischler, revisión de mitad de periodo de las reformas de la Agenda 2000). Se estableció que las cuotas lecheras serían eliminadas para el año 2013. Según Zahrnt: «Las cuotas se usan para proteger los recursos naturales como el pescado pero no para generar rentas a los productores. ¿Por qué debería privilegiarse a los productores de leche sobre otros sectores tanto agrícolas como no agrícolas?» (Zahrnt, 2010). Sin embargo, en el año 2009, debido mayormente a la sobreproducción, los precios europeos de la leche para los productores eran a principios de año extremadamente bajos - menos de 20 céntimos de euro ( 0,29 dólares) por litro cuando dos años antes el precio se ubicaba en 40 céntimos. En lugar de reducir la producción para estabilizar los precios, la UE reintrodujo los subsidios a la leche para apoyar a los productores en el 2009. «Como consecuencia, la UE nuevamente se encuentra exportando leche a todo el mundo subdesarrollado, especialmente a África, a precios de dumping... al hacer esto, la UE está destruyendo el sustento de los granjeros en los países más pobres del mundo mientras mantiene artificialmente un nivel de producción muy alto» (Godoy, 2010).

Las políticas agrarias de la UE han incrementado los precios en un 12 por ciento en el año 2008, transfiriendo 36 mil millones de euros de los consumidores a los productores. Esto es particularmente dañino para las familias de bajos ingresos que gastan una proporción relativamente alta de los mismos en alimentos. Según Eurostat del 2010 la comida, la bebida y el tabaco constituyen aproximadamente el 25 por ciento de los gastos del último quintil de ingresos familiares de la UE, mientras que esta proporción representa solo un 15 por ciento del gasto para las familias del quintil superior (Eurostat, 2010). En consecuencia, los consumidores pobres están pagando una parte desproporcionada de la factura total. 
La Unión Europea gasta cerca de 75 mil millones de dólares en subsidios a la agricultura aun cuando el sector representa solo el dos por ciento del PIB total de la unión. Recientemente se ha revelado que las subvenciones agrícolas crecieron hasta el 22 por ciento en el año 2009, desde el 21 por ciento del 2008 (OCDE, 2010). Cerca del 90 por ciento de la producción de la UE se encuentra protegida de algún modo por la PAC, con un 70 por ciento recibiendo subsidios a los precios.

También se ha destacado que la PAC es un factor que contribuye a la decadencia de la salud europea de los últimos años. El azúcar artificialmente barato utilizado como agente espesante así como endulzante en una amplia gama de alimentos y bebidas dulces y saladas ha llevado al incremento en el consumo y está contribuyendo a los crecientes niveles de sobrepeso y obesidad. Al subsidiar fuertemente la leche y la carne se aseguran que los alimentos con alto contenido de grasas saturadas sean comparativamente más accesibles para personas de bajos recursos de lo que serían en otras circunstancias. En contraste, las frutas y verduras, que reciben poco apoyo de la PAC son relativamente caras. Un alimento barato con alto contenido de grasas y azúcares y frutas y vegetales caros contribuyen a la pobreza alimenticia, es decir, a la incapacidad de pagar o tener acceso al tipo de alimento que constituye una dieta saludable. Esta desigualdad en la dieta predispone la desigualdad en las enfermedades relacionadas con la alimentación (las personas de bajos ingresos tienen tasas más altas de enfermedades coronarias, obesidad y diabetes). Un estudio lo resume muy bien:

En conclusión, este estudio indica que, desde su creación, los subsidios y las políticas de set-aside de la PAC pueden haber sido responsables de cientos de miles de muertes prematuras a lo largo de la Unión Europea. Es probable que las verdaderas cifras sean incluso mucho mayores que las conservadoras mencionadas más arriba. La reforma de las políticas actuales de la PAC desplegada en este informe podría, entonces, prevenir un gran número de muertes adicionales. (Birt, 2007). 


\section{XII ¿HAY ESPERANZAS PARA EL FUTURO?}

La Unión Europea se enfrenta a una decadencia a largo plazo debida a la interacción de poblaciones envejecidas, sistemas de pensiones sin fondos, caída de la competitividad y sobreendeudamiento de los gobiernos. El porcentaje de comercio intereuropeo llegó a su pico máximo en 1992 y viene cayendo desde entonces (Open Europe, 2005). Los rígidos mercados laborales, los rígidos precios de los factores, la excesiva regulación, los elevados impuestos y una fuerza laboral en descenso están en marcado contraste con los bajos impuestos, las menores regulaciones, el auge del «baby boom» y el comercio abierto de la Europa de los años '50 y '60 que rápidamente alcanzó a los Estados Unidos después de la Segunda Guerra Mundial. Como el Instituto Francés de Relaciones Internacionales escribiera en el año 2002: «La ampliación de la Unión Europea no será suficiente para garantizar la igualdad con los Estados Unidos. La Unión Europea tendrá cada vez menor peso en el proceso de globalización y es de esperar un lento pero inexorable movimiento hacia la irrelevancia total» (Institut Français des Relations Internationales, 2002).

El profundo clientelismo europeo siempre obstaculizará cualquier reforma real. Tras cincuenta años de propaganda, la verdad acerca de por qué la PAC continua existiendo ha sido mejor resumida por Pascal Lamy, el Comisionado Europeo francés, quien declaró: «La Unión Europea ha tomado deliberadamente la decisión de mantener a sus granjeros en la tierra, sean o no competitivos a nivel internacional... Si fuéramos totalmente competitivos, el empleo en el sector agrícola caería de 7 millones a solo un millón. Esto es políticamente inaceptable» (citado en Legum, 2002).

Y esta es la realidad. No existen motivos económicos o científicos o medioambientales o sociológicos para defender la PAC. Cuando todos los argumentos son analizados en profundidad, nos queda solo una pizca de verdad: la PAC existe solo para que algunas elites políticamente bien conectadas puedan enriquecerse a costa de todos los demás. La concentración de grupos especiales de interés deja indefensas a las dispersas y desorganizadas masas 
frente a las grandes prerrogativas especiales que la UE ha garantizado de manera permanente.

Intelectualmente, la PAC está destrozada. Ha fracasado en todos sus objetivos. La única área en la que nominalmente ha tenido éxito ha sido en la elevación del ingreso de algunos pocos productores. Como hemos visto, la gran mayoría de los productores agrícolas ha sido, de hecho, expulsada de sus tierras. Cuando despejamos la pseudociencia y la falsa preocupación por el prójimo nos quedamos con una enorme factura a cargo de los contribuyentes que daña regresivamente a los pobres y que se dirige directamente a un puñado de productores ricos. Así es como la PAC ha actuado siempre, desde el comienzo.

Quisiera dejarles dos citas que podrán guiarnos en cuanto a lo que podemos esperar de la PAC en el futuro. Uno de estos puntos de vista será el vencedor, y la vida de muchos depende de cuál sea.

«Debemos inventar nuevos métodos de intervención... necesitamos protección para defender los productos nacionales y europeos de la competencia extranjera... Es tiempo de que nazca un verdadero patriotismo económico europeo.» Dominic de Villepin, Primer Ministro francés durante el período 2005/07.

En contraste, cuando Frédéric Bastiat, el caballero intelectual de la Francia liberal, condenó en 1850 a los tiranos de su época, habló en solidaridad con los pobres y marginados de su país. Él escribió:

Para robarle al público es necesario engañarle. Para engañarle se le debe persuadir de que se le está robando en su propio beneficio e inducirle a aceptar, a cambio de su propiedad, servicios que son ficticios o, a menudo, aun peores. Este es el propósito de la sofistería, sea tecnocrática, económica, política o monetaria... Cuando el saqueo se transforma en una forma de vida para un grupo de hombres que viven en sociedad, a través del tiempo crean para sí mismos un sistema legal que lo autorice y un código moral que lo glorifique. (Bastiat, 1845). 


\section{REFERENCIAS BIBLIOGRÁFICAS}

ACKRILL, R., Hine, R.C., and RAYNER, A. (1998): «CAP reform and implications of Member States: budget and trade effects», in The Reform of the Common Agricultural Policy, A. Rayner and R.C. Hine. (eds.), Basingstoke: Macmillan, pp. 104-131. Ackrill, R. (2005): «Common Agricultural Policy», in Handbook of Public Administration and Policy in the European Union, Peter van der Hoek (ed.), Boca Raton: CRC Press, pp. 435-487.

- (2008): «The CAP and its Reform: Half a Century of Change?» EuroChoices, 7 (2): 13-21.

Ahern, B. (2005): «Taoiseach defends funding of the Common Agricultural Policy (CAP)», Department of the Taoiseach. September 9. http:/ / www.taoiseach.gov.ie/eng/Government Press_Office/Taoiseach's_Press_Releases_2005/Taoiseach_ defends_funding_of_the_Common_Agricultural_Policy_ CAP_html.

UK TAXPAYERS Alliance (2009): Food for Thought: How the Common Agricultural Policy Costs families over $£ 400$ a year. The Taxpayers Alliance.

Bagus, P. (2010): The Tragedy of the Euro. Auburn, AL: Ludwig von Mises Institute. En Español La Tragedia del Euro, Unión Editorial, Madrid, 2011.

BARNIER, M. (2008): «How Europe should tackle the global food crisis», Europe's Workd, http://www.europesworld.org/ NewEnglish / Home_old / Article/tabid / 191/Article Type/articleview / ArticleID/21209/language/en-US / Default.aspx

Bastiat, F. ([1845] 1996): Economic Sophisms Parts One E Two, (trans.) A. Goddard. Irvington-on-Hudson, NY: Foundation for Economic Education.

BIRT, C. (2007): A CAP on Health? The Impact of the Common Agricultural Policy on Public Health, London: Faculty of Public Health.

Bolin, O. and SwedenborG, B. (1992): «Mat till EG-pris», SNS Förlag.

BRooks, J. (2003): «Agriculture: Why is it still so difficult to reform?» OECD Observer, http://oecdobserver.org/news/ 
fullstory.php/aid/1177/Agriculture:_Why_is_it_still_so_ difficult_to_reform_.html

Caplan, B. (2007): The Myth of the Rational Voter, Princeton University Press.

Collins, N.R. (1963): «Discussion: The European Common Market and Agriculture», Journal of Farm Economics, 45 (5): 993-996.

Commission of THE European Communities (1998): «Proposals for Council regulations (EC) concerning reform of the common agricultural policy», EU.

EuropeAn Commission (1997): «Towards a Common Agricultural and Rural Policy for Europe», The Report of an Expert Group, Brussels.

- (2007): EU Budget.

CONWAY, G. (1998): The doubly green revolution: food for all in the twenty-first century. Ithaca: Comstock Publishing.

Cooper, T., Hart, K. and BALdock, D. (2009): Provision of Public Goods through Agriculture in the European Union. Institute for European Environmental Policy.

Coppock, J.O. (1963): The North Atlantic Policy-The Agricultural Gap. New York: The Twentieth-Century Fund.

CSAKI, C. (2008): «The CAP at Fifty», EuroChoices Volume 7 (2): 4-5. Directorate-Generale For Agriculture and Rural DeVElopment (2008): From 1980 to 2006: CAP expenditure - European Commission, DG Agriculture and Rural Development (Financial Reports). European Commission. 31

ECIPE (2009): «A Common Agricultural Policy for European Public Goods», European Centre for International Political Economy (ECIPE), http:/ / www.ecipe.org/archived-events / a-common-agricultural-policy-for-european-public-goodsdeclaration-by-a-group-of-leading-agricultural-economists

EU Business LTD. (2010): «EU to Put Cereal Stocks on Market by End of Year», September 27, http:/ / www.eubusiness.com/ news-eu/farm-food.6ao

EUROPEAN COMMISSION (2008): «Proposal for a Directive of the European Parliament and of the Council on the promotion of the use of energy from renewable sources» EUR-Lex.europa.eu. Jan 23, http:/ / eur-lex.europa.eu/LexUriServ /LexUriServ. do?uri=COM:2008:0019:FIN:EN:HTML 
- (2010): «The EU's Common Agricultural Policy (CAP): on the move in a changing world How the EU's agriculture and development policies fit together», European Commission Agriculture and Rural Development.

Eurostat (2010): Eurostat Pocketbook: Key Figures on Europe.

FISCHLER, F. (2008): «Europe's CAP: Changes and Challenges», EuroChoices 7 (2): 22-27.

FISCHLER, F. (2010): «Foreword from the Chairman Dr. Franz Fischler», Rise Foundation, November 24, http://www. risefoundation.eu/index.php?option $=$ com_content\&view $=$ article\&id $=48 \&$ Itemid $=64$

Godoy, J. (2010): «Farm Subsidies on Increase», Asia Times, August 10, http://www.atimes.com/atimes/Global_Economy / LH10Dj05.html

Hall, B. (2008): The Rising Cost of Food: Europe's CAP the "Answer» to Food Crisis. April 27, http://www.ft.com/cms/s/0/ 939ee094-148d-11dd-a741-0000779fd2ac.html?nclick_ check=1

Harvey, D. (1988): «Food Mountains and Famines: The Economics of Agricultural Policies», Inaugural Lecture at the University of Newcastle upon Tyne. Newcastle: Newcastle University, March 3.

- (2008): «Happy Birthday to The CAP»-Comment on the CAP's 50th Birthday', EuroChoices 7 (2): 54.

Hasha, G. (1999): The European Union's Common Agricultural Policy: Pressures for Change-An Overview, United States Dept. of Agriculture, Economic Research Service.

HAYEK, F. (1948): «The Use of Knowledge in Society», The American Economic Review 35: 519-30. 32

- (1989): The Fatal Conceit: The Errors of Socialism. Chicago: University of Chicago Press. En Español: La Fatal Arrogancia, los Errores del Socialismo, 3. ed., Unión Editorial, Madrid, 2010.

Hill, B. (2008): «Using the Wye Group Handbook to develop EU statistics on the incomes of agricultural households», Journal of Agricultural Economics 59 (3): 387-420.

Huerta De Soto, J. (2010): Socialism, Economic Calculation and Entrepreneurship. Cheltenham, Inglaterra; Edward Elgar. En 
español, Socialismo, cálculo económico y función empresarial, 4. ${ }^{a}$ ed., Unión Editorial, Madrid 2010.

Human Development Reports (2005): International cooperation at a crossroads: Aid, trade and security in an unequal world. United Nations Development Program.

Institut Français des Relations Internationales (2002): World Trade in the $21^{\text {st }}$ century. Brussels: European Commission. JongenEel, R (2010): «European Dairy Policy in the Years to Come: Quota Abolition and Competitiveness», LEI Report.

LEARN, E.W. (1963): «The Impact of European Integration on American Agriculture», Journal of Farm Economics, 45 (5): 983-991.

Legum, M. (2002): It doesn't have to be like this-Global economics a new way forward. Glasgow: Wild goose Publications.

LuDLOW, N.P. (2005): «The making of the CAP: Towards a historical analysis of the EU's first major common policy», Contemporary European History, 14 (3): 347-371.

Mises, L. vON ([1949] 1998): Human Action : A Treatise on Economics, Auburn, AL : Ludwig von Mises Institute. En Español: La Acción Humana, 10.ํ ed., Unión Editorial, Madrid, 2011.

Mitchell, D. (2008): A Report on Rising food Prices. World Bank. Mortished, C., and Webster, P. (2008): France's Answer to Global Food Crisis is EU Protectionism', Times Online, April 15, http:/ / www.timesonline.co.uk/tol/news/world/europe/ article3746899.ece

OECD (2003): «Agricultural Policies in OECD Countries: A Positive Reform Agenda», OECD Observer.

- (2010): «Agricultural Policies in OECD Countries at a Glance», OECD.

Open Europe (2005): «Open Europe: Why the EU must reform to Survive», http:/ /www.openeurope.org.uk/research/ factsheet.pdf

PaArlberg, D., and PAarlberg, P. (2000): The Agricultural Revolution of the $20^{\text {th }}$ Century, Ames, Iowa State University Press.

PAarlberG, D. (1964): «Reviewed Works: North Atlantic Policy: The Agricultural Gap by John O. Coppock.» The American Economic Review, 54 (4): 508-510.

PARsons, C. (2003): «A Certain Idea of Europe», Cornell University Press. 33 
Peeters, K. (2008): «A Competitive, Sustainable and Diverse Agriculture: A View of the CAP Beyond 2013», EuroChoices 9: 49.

Petit, M. (2008): «The CAP After Fifty Years: A Never-Ending Reform Process», EuroChoices, 7 (2): 55.

Pirzio-Biroli, C. (2008): «An Insider's Perspective on the Political Economy of the Fischler Reforms», Centre for European Policy Studies, 102-114.

Pото NIK, J. (2010): "Can the CAP bring considerable benefits to our environment?» $3^{\text {rd }}$ Forum for the Future of Agriculture The Economics and Politics of Food Security vs. Climate Change. Brussels.

Rabinowicz, E. (2004): «The Swedish Agricultural Policy Reform of 1990- A Window of Opportunity for Structural Change in Policy Preferences», Adjusting to Domestic and International Agricultural Policy Reform in Industrial Countries. Philadelphia: International Agricultural Trade Research Consortium.

REUTERS (2010): «U.S. corn ethanol "was not a good policy"-Gore», Nov 22, http://af.reuters.com/article/energyOilNews / idAFLDE6AL0YT20101122? pageNumber=2\&virtual BrandChannel $=0 \&$ sp $=$ true

RIEger, E. (2005): «Agricultural Policy: Constrained Reforms», in Policy-Making in the European Union, W. Wallace and M.A. Pollack (eds.), Oxford University Press, pp. 161-190.

Rodale InSTITUTE (2002): Farming without subsidies? Some lessons from New Zealand. http://newfarm.rodaleinstitute.org/ features/0303/newzealand_subsidies.shtml

Rothbard, M.N. ([1963] 2004): America's Great Depression, Alabama, AL: Ludwig von Mises Institute.

- (1973): For a New Liberty: The Libertarian Manifesto, Collier Macmillan.

- (1982): The Ethics of Liberty, New Jersey: Humanities Press. RYAN, R. (2010): «Strong CAP needed to help farmers cope with regulations, says Walshe», Irish Examiner, July 21, http:/ / www.irishexaminer.com/business/kfcwojgbgboj/rss2/ \#ixzz15d4jtq53 (accessed 11 2010, 18)

SAMUELSON, P.A. (1954): «The pure theory of public expenditure», Review of Economics and Statistics, 36 (4): 387-389. 
SCHumPeter, J.A. (1942): Capitalism, Socialism and Democracy. London: Unwin.

SPOERER, M. (2010): «Fortress Europe in long-term perspective: agricultural protection in the European Community, 19572003», Journal of European Integration History, (forthcoming).

STEAD, D.R. (2008): «The Birth of the CAP», EuroChoices, 7 (2): 612.

SWinnen J. and Gorter, H. DE (2002): «On Government Credibility, Compensation, and Underinvestment in Public Research», European Review of Agricultural Economics, 29 (4): 501-22.

Thurston, J., Mulvad, N. and Alfter, B. (2010): «Reaction to ECJ ruling», Farm Subsidy, November 9, http:/ / farmsubsidy.org/ news/features/ecj-reaction/

TOEPFER INTERNATIONAL (2007): «Biofuels to keep global grain prices high», Reuters, July 30, http:/ / www.reuters.com/article / idUSL309054420070730 (accessed 2010)

UNEP (2009): Towards Sustainable Production and Use of Resources: Assessing Biofuels. United Nations Environment Program.

VAGlenov, S. and BAlabanova, T. (2010): «A Family Affair: Bulgarian farming minister distributes EU money among his family», Farm Subsidy September 16, http:/ / farmsubsidy.org/ news/features/family-affair/

Villepin, D. DE (2005): L'Homme européen. Plon.

Walt, V. (2010): «Even in Hard Times, E.U. Farm Subsidies Roll On», Time, May 14, http://www.time.com/time/business/ article/0,8599,1989196,00.html\#ixzz161g83cuA

ZAHrnt, V. (2010a): «Declaration on CAP Reform», Euro Choices, 9 (1): 57.

- (2010b): Financing the Common Agricultural Policy: Which member states pay for the waste of public money? European Centre for International Political Economy.

Zовве, H. (2002): «The Economic and Historical Foundation of the Common Agricultural Policy in Europe». Xth EAAE Congress Exploring Diversity in the European Agri-Food System. Zaragoza, Spain: European Association of Agricultural Economists. 